\title{
Do Infants and Children have Measurable Inguinal Canals?
}

\author{
Osuoji RI' ${ }^{1}$, Bankole MA ${ }^{2}$ \\ ${ }^{1}$ Dr. Roland I. Osuoji, BMBCH, FMCS, FICS, FWACS \\ Consultant Paediatric Surgeon/Senior Lecturer, ${ }^{2} \mathrm{Dr}$. \\ Michael A. Bankole, MBBS, FACS, FAAP, FMCS, \\ FWACS, FICS. All from the Paediatric Surgery Unit, \\ Department of Surgery, Lagos State University Teaching \\ Hospital, Ikeja, Lagos, Nigeria.
}

\section{Introduction}

$\mathrm{H}_{\mathrm{s}}^{\mathrm{cos}}$ erniotomy remains one of the most frequently performed surgical procedures in childhood ${ }^{1}$, However, opinions differ as to whether to open the inguinal canal while performing the procedure as proposed by Ferguson and Gross ${ }^{2}$, or not to open it as proposed by Mitchell Banks. The reason for the latter procedure being the superimposition of the superficial ring on the deep ring sometime during childhood ${ }^{3}$. This prospective study was aimed at corroborating or refuting this hypothesis.

\section{Materials and Methods}

From October 2007 to September 2008, and from May 2012 to April 2013, children up to two years and below with a diagnosis of communicating hydrocoeles, inguinal hernias, encysted hydrocoeles of the cords, and truly undescended testes were operated on by two Consultant Paediatric Surgeons in our unit. Under general anaesthesia with the child in the supine position, the abdomen was cleansed and draped. A skin crease inguinal incision was made, the medial end of incision just supero-lateral to the pubic tubercle, the incision was deepened through the Camper's fascia and the Scarpa's fascia to expose the external oblique aponeurosis which was opened along its fibres to open the inguinal canal. The lateral flap was elevated, taking care to identify and protect the underlying delicate ilioinguinal nerve. The pubic tubercle was palpated at the infero-medial end of the inguinal canal, the inferior epigastric vessels were identified supero-medial to the deep inguinal ring, using a sterilized metallic ruler (Fig 1), and the distance between the two structures was measured in centimeters. A herniotomy with a high ligation of the sac using a non-absorbable suture at the level of the inferior

\footnotetext{
Address for correspondence

Dr. Roland I. Osuoji

Lagos State University Teaching Hospital,

Ikeja, Lagos, Nigeria.

E-mail: drosuoji@yahoo.com
}

This work is licensed under a Creative Commons Attribution 3.0 License.

\begin{abstract}
Introduction: Herniotomy is a common procedure performed by Paediatric Surgeons. However, opinions differ as to whether to open the inguinal canal when performing this procedure or not. Those who advocate performing herniotomy without opening the inguinal canal believe that in early childhood, the superficial inguinal ring is directly superimposed on the deep inguinal ring, there being no appreciable inguinal canal in this age group. Our study was planned to open the inguinal canal and simply measure the distance between the pubic tubercle medially and the inferior epigastric vessels laterally. Finding a measurable inguinal canal in all cases studies debunks the belief that the superficial inguinal ring frequently overlaps the deep inguinal ring. Materials and Methods: From October 2007 to September 2008 and from May 2012 to April 2013 the inguinal canals of 75 children from 1 day to 2 years old were measured during herniotomies and orchidopexies. Premature babies were excluded from this study. The inguinal canals were all opened. Using a simple sterilized metallic ruler, the distance between the ipsilateral inferior epigastric vessels and the ipsilateral pubic tubercle was measured. Results: The lengths of the inguinal canals ranged from $1 \mathrm{~cm}$ to $4.5 \mathrm{~cm}$ (mean $2.88 \mathrm{~cm}+/-.71 \mathrm{~cm} \mathrm{SD}$ ). The shortest inguinal canal length was $1 \mathrm{~cm}$ while the longest inguinal canal was $4.5 \mathrm{~cm}$. Conclusion: Children with inguinal hernia up to the age of 2 years have a measurable inguinal canal and we suggest the excision of the hearnial sac superficial to the external inguinal ring runs the risk of leaving substantial sac behind proximal to the transfixing suture, even when some traction is applied to the sac before applying the transfixing suture.
\end{abstract}

Key words: Herniotomies, inguinal canals in children.

epigastric vessels, was done to complete the process. The wound was closed in layers.

\section{How to cite this article?}

Osuoji RI, Bankole MA. Do Infants and Children have Measurable Inguinal Canals? J Nepal Paediatr Soc 2013;33(3):182-185. 


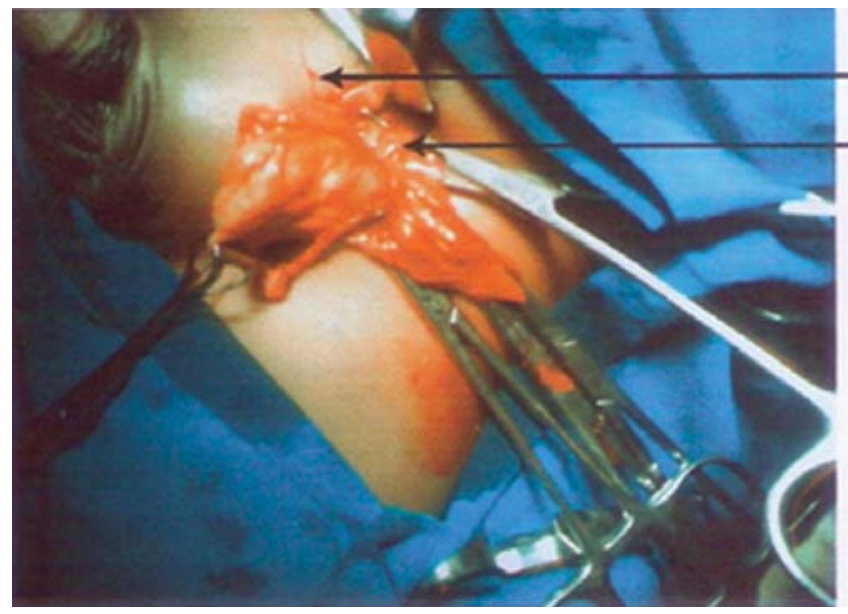

Fig. 1: Shows the inguinal canal of a 1 year old male child with an inguinoscrotal hernia

\section{Results}

Seventy six inguinal canals were measured in 72 males and 3 females, 1 male $(1.3 \%)$ had bilateral inguinal hernias. Seventeen (22.6\%) had right inguinoscrotal hernias, 7 (9.3\%) had left communicating hydrocoeles, another 7 (9.3\%) had left inguinoscrotal hernia, $16(21.3 \%)$ had left inguinal hernia, $2(2.6 \%)$ had left undescended testes, $1(1.3 \%)$ had a left vaginal hydrocoele, $2(2.6 \%)$ had a right communicating hydrocoeles, $20(26.6 \%)$ had right inguinal hernias, and $3(4 \%)$ had right undescended testes. The lengths of the inguinal canals ranged from $1 \mathrm{~cm}$ to $4.5 \mathrm{~cm}$ (mean $2.88 \mathrm{~cm}+/-.71 \mathrm{~cm} \mathrm{SD}$ ). The shortest inguinal canal length was $1 \mathrm{~cm}$ in a 2 months old male child who had a right inguinoscrotal hernia, while the longest inguinal canal was $4.5 \mathrm{~cm}$ and belonged to a 7 months old male child that had a left inguinoscrotal hernia (see Fig 2).
PUBIC TUBERCLE

INFERIOR

EPIGASTRIC

VESSELS

\section{Discussion}

The anatomy of the undisturbed canal has the following features:

(i) The pubic tubercle is the attachment of the lateral limb of the superficial (external) inguinal ring (the medial limb fuses with the anterior rectus sheath).

(ii) The midpoint of the inguinal ligament (the midway between its origin in the anterior superior iliac spine and its insertion in the pubic tubercle) is the standard surface marking of where the external iliac artery gives off its last branch in the abdomen, passes behind the inguinal ligament, and becomes the femoral artery.

(iii) This last branch is the inferior epigastric artery and it runs supero-medially just deep to the tranversalis fascia to form the medial limit of the deep (internal) inguinal ring, and the lateral border of the Hesselbach's triangle in its upward course to enter the rectus sheath lying between the rectus muscle and the posterior rectus sheath ${ }^{4,5,6,7}$.

(iv) Against the background of these anatomical considerations, it is obvious that the inguinal canal extending from the deep inguinal ring to the external inguinal ring has a definable, and a definite length that relates to the medial half of the inguinal ligament.

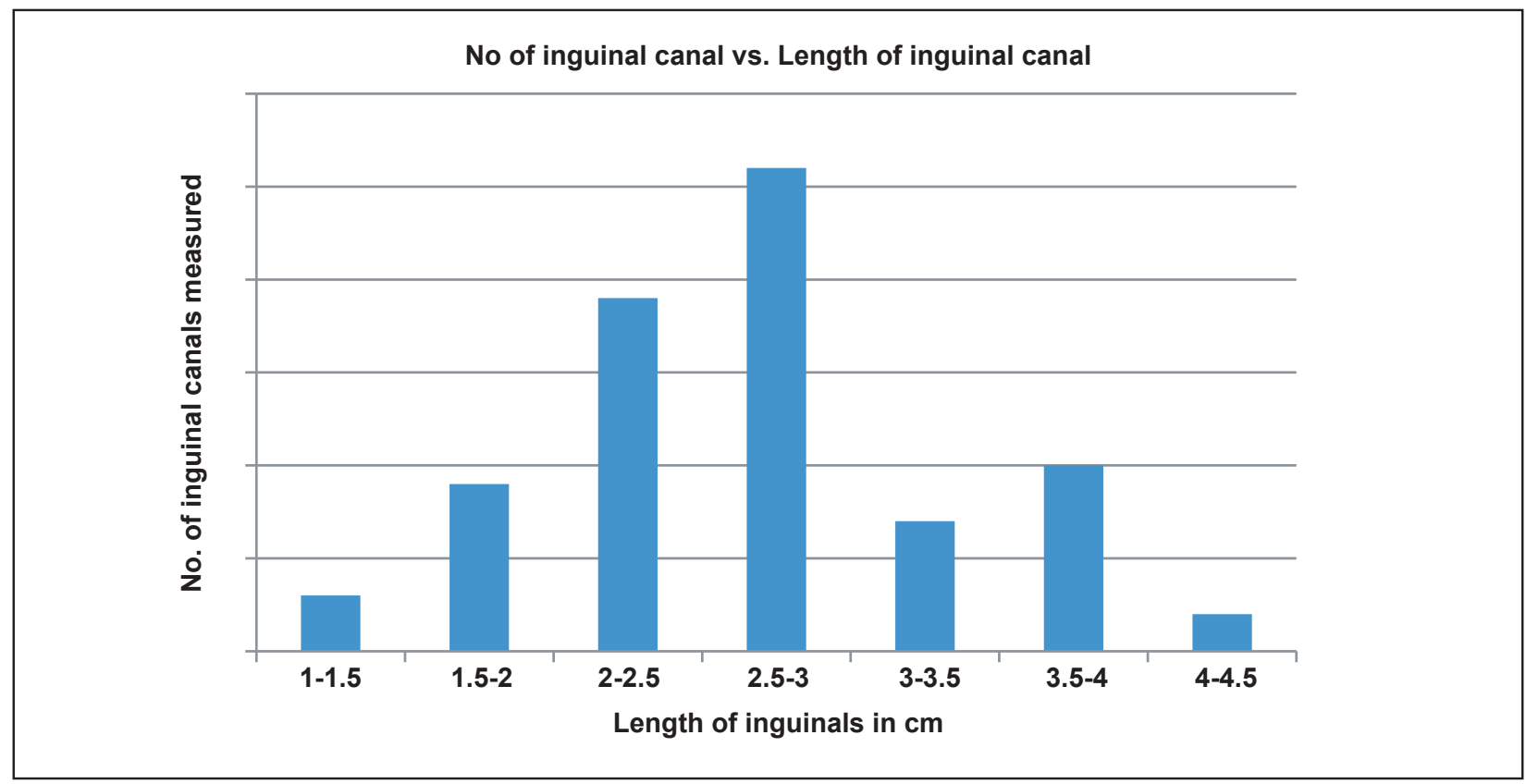

Fig. 2 
(v) Finally, in the clinical condition of the truly undescended testes, there is a group in which the testes is arrested in the inguinal canal ${ }^{8}$ and can be distinctly palpated lateral to the pubic tubercle, and clearly not intra-abdominal i.e. it has "passed" through the deep (internal) inguinal ring.

Herniotomies are commonly done by Paediatric Surgeons, two approaches are used; the Ladd and Gross procedure, and the Mitchell-Banks procedure, although laparoscopic herniotomy has come into the picture $^{9}$. The former method, which we used, entails making an inguinal incision which is deepened by incising the Camper's and Scarpa's fasciae to expose the external oblique aponeurosis, which is incised along its fibres to open the inguinal canal, the ilioinguinal nerve is seen and avoided, the cremasteric fascia is incised, to expose the vas, its blood supply, and the hernia sac. The sac is separated from the vas and its blood supply, with further dissection, the sac is mobilized to the level of the preperitonial fat and ligated with nonabsorbable sutures. The wound is closed in layers. In Mitchell-Banks method, an inguinal incision is made, two $\mathrm{cm}$ long sited over the superficial inguinal ring. The incision is deepened through layers sequentially: Camper's fascia, Scarpa's fascia, the spermatic cord is identified as it emerges from the superficial ring, distal to the ring, the cord is covered by external spermatic fascia and cremasteric fascia. These must be split, and this separates the vas deferens and vessels from the sac. The sac is pulled as much as possible, gently, out of the inguinal canal through the superficial ring. It is ensured that the sac is empty and is ligated as proximally as possible with absorbable sutures. The wound is closed in layers.

The controversy has continued over which procedure to adopt when performing childhood herniotomies. K Ravi and DB Hamer ${ }^{10}$ did a study in which they surveyed the surgical treatment of inguinal hernias in children in the United Kingdom, and came up with the conclusion that there was obviously no standard surgical technique for inguinal herniotomy in children, and there were only trends. In children under the age of two years, most surgeons surveyed performed the operation superficial to the external ring, although a higher proportion of surgeons at specialist units opened the inguinal canal routinely. In a similar article, Sklar C, and Cameron $\mathrm{BH}^{2}$, noted that most American Surgeons opened the inguinal canal, others preferred the MitchellBanks method, and advised the opening of the inguinal canal to effect the high ligation of the sac to prevent recurrence ${ }^{1}$.

In our paediatric surgical unit, we decided to put the issue finally to rest by physically measuring the distance between the pubic tubercle and the inferior epigastric artery, after carefully developing our inguinal incision by sharp dissection from skin, through the Camper's fascia, Scarpa's fascia, and incising the external oblique aponeurosis, avoiding undue traction or retraction at this stage.

It is true that one may get away with doing herniotomy without incising the external oblique aponeurosis to open the inguinal canal during childhood herniotomies. This is achieved by exerting considerable traction on the hernia sac. Quite often, the protagonists of this method do not insist on viewing the inferior epigastric vessels which we did in all the cases studied, (may be absent in a malnourished child), and therefore leave behind a short sleeve of hernia sac proximal to the point of herniotomy- a recipe for recurrence ${ }^{1}$.

Indeed another good reason for exposing and identifying the internal ring is that, especially in relatively large herniae, the canal may become so long, and the deep inguinal ring so large as seen in one of our patients as to readily admit an examining finger after the hernia sac had been transfixed and excised. That defect could be easily repaired by narrowing the ring.

Another pitfall sometimes encountered by those who limit their dissection to the area of the superficial ring without opening the external oblique aponeurosis is that when they do not readily find the hernia sac, and in the mistaken basic belief that the deep ring is just deep to the superficial ring, they plough deeper through the conjoint tendon and encounter the distended urinary bladder which they mistake for "an unusually thick hernia sac".

\section{Conclusion}

We conclude that children have well defined, definite, and measurable inguinal canals and these should be routinely opened during herniotomies.

Acknowledgements: None

Funding: None

Conflict of interest: None

Permission from IRB: Yes

\section{References}

1. Jay L. Grosfeld, Kathryn Minnick, Frederick Shedd, et. al: Inguinal Hernia in Children: Factors Affecting Recurrence in 62 Cases, Journal of Pediatric Surgery, Vol. 26, No. 3 (March), 1991: pp283-287.

2. Sklar C. and Cameron B. H. (2008). Achieving excellent outcomes and avoiding complications in pediatric inguinal hernia surgery. http://goo.gl/ P6HXW Retrieved on May 20, 2013. 
3. Phillip L. Glick, Scott C. Boulanger: Inguinal hernias and hydrocoeles, in Grosfeld J.L., O'Neill J.A., Coran A.G. et al. (eds): Pediatric Surgery, Mosby Elsvier Year Book Publishers, 2006, p1177.

4. Abdomen, in Russell T., Wood Burne A.M., (ed): Essentials of Human Anatomy. Sixth Ed. New York Oxford University Press, 1978, pp379-381.

5. Abdomen and pelvis, in Harold and Vishy Mahadevan (eds): Clinical Anatomy, Twelfth Edition, Wiley-Blackwell Publishers, 2010, pp S70-71.

6. Stanley Salmons: Muscle, in Lawrence H. Bannster, Martin M. Berry, Partricia Collins et al., (eds): Gray's Anatomy, 38 ${ }^{\text {th }}$ Ed., Churchill Livingstone Publishers, 1995, pp 822, 829.
7. Abdomen, in C.S. Sinnatamby (ed), Last's Anatomy, Regional and Applied,Eleventh Edition, Churchill Livingstone Elsevier Publishers, 2006, pp 234-236.

8. Descent of the testes, in Sadler T.W., (ed): Langman's Medical Embryology, 10 $0^{\text {th }}$ ed. Lippincott Williams \& Wilkin Publishers, New Delhi, 2006, pp253-255.

9. Niyogi A., Tahim A.S., Sherwood W.J., De Caluwe D. et al.: A comparative study examining open inguinal herniotomy with and without hernioscopy to laparoscopic inguinal hernia repair in a pediatric population, Pediatric Surg Int. 26 (4): Apr, 2010: pp387-92.

10. Ravi K, \& Hamer D.B. (2003). Surgical treatment of inguinal hernia in children. Hernia, 7(3), 137-140 http://goo.gl/owj94 Retrieved on 20 th May, 2013. 